is formidable.

Of course, I appreciate that, in practice, proximity may often be the only measure available, and it would indeed be expected to correlate with choice. It is surprising that, in my data, spurs are so insignificant. It is possible that the males from which females solicit copulations are not always the same as those they feed near. The combination of my studies and those of Von Schantz et al. ${ }^{1}$ suggest either that Swedish pheasants are differently choice-oriented from their British counterparts, or that measuring female preference by distance from the male rather than by actual copulation solicitation is misleading.

\section{Department of Zoology,}

Nigella HiLLgarth

\section{University of Oxford,}

Oxford OX1 3PS, UK

1. von Schantz, T. et al. Nature 337, 166-169 (1989).

2. Weatherhead, P. J. \& Hoysak, D. J. Nature 343, 599-600 (1990).

(1990).

3. Kirkpatrick, M. Nature 337, 116-117 (1989)

4. Savalli, M. Nature 339, 432 (1989)

5. Ridley, M. E. \& Hill, D. A. J. Zool. 211, 619-630 (1987)

\title{
Retroviral antibodies in Indians
}

SIR - In February last year, two of us (G. H. and R. W.) took part in the Tapirapeco expedition into the rainforest of the upper Mavaca River, a tributary of the Orinoco. We visited three remote Yanomami villages (shabonos), Mishimishiporepithiwe, Washewe and much lower than the 13.7 per cent reported earlier for Venezuelan Amazonian Yanomani indians".

These differences reflect either the complete isolation of the population which we have examined or, once again, technical difficulties in analysing sera

ANTIBODIES AGAINST HTLV-1 AND TYPE-D RETROVIRUSES IN YANOMAMIS

Antibody-positive-individuals

\begin{tabular}{lcccc} 
Village & $\begin{array}{c}\text { Sample } \\
\text { No. }\end{array}$ & Virus & $\begin{array}{c}\text { No. } \\
\text { positives }\end{array}$ & $\begin{array}{r}\text { Individual } \\
\text { (age, sex) }\end{array}$ \\
\hline Mishimishiporepithiwe & 112 & $\begin{array}{l}\text { HTLV-1 } \\
\text { type-D } \\
\text { HTLV-1 } \\
\text { type-D }\end{array}$ & 1 & $10 \mathrm{M}$ \\
Washewe & 82 & HTLV-1 & 2 & $8 \mathrm{M}, 8 \mathrm{~F}$ \\
Peripapuey & 69 & type-D & 0 & $35 \mathrm{M}, 7 \mathrm{~F}$ \\
& & 3 & $30 \mathrm{M}, 35 \mathrm{~F}$,
\end{tabular}

Peripapuey, took 263 blood samples, representing about 90 per cent of the inhabitants of these villages, excluding very small children. We prepared sera in the base camp and then shipped samples to Germany.

There, we examined the samples for antibodies against five retroviruses: human immunodeficiency virus (HIV) types 1 and 2; human T-lymphotropic virus type I (HTLV-1) $)^{1.2}$; human foamy retrovirus (HFRV), and simian type-D retrovirus $(\mathrm{SRV}-1)^{4}$. We had earlier demonstrated the specificity of our HIVand HTLV antibody tests using African sera $^{1,2}$. We found antibodies against HTLV-1 in only three samples and against SRV-1 in only five samples. We observed no obvious signs of disease that might be related to HTLV-1 or type-D virus infection. In addition, sera from 18 military personnel and 17 Makiritare indian workers from the base camp were negative in all five assays.

Our results confirm and extend an earlier report ${ }^{5}$ but differ from observations by Volsky and co-workers, who described HIV serum antibodies in Venezuelan Pemon and Yanomami indians ${ }^{6.7}$ and also the isolation of an HIV-related virus from such a sample ${ }^{8}$. Moreover, the prevalence of HTLV-I antibodies in our sample was from tropical regions ${ }^{1.3}$. In addition, a type-D retrovirus has been isolated from squirrel monkeys (Saimiri sciurcus) ${ }^{10}$. However, the significance of serum antibodies in Yanomamis to type-D viruses remains to be determined.

\section{Abteilung Virologie \\ und Immunologie, \\ Deutsches Primatenzentrum, \\ Kellnerweg 4, \\ 3400 Göttingen, FRG}

ROLF M. FLÜGEL

Deutches Krebsforschungszentrum,

Im Neuenheimerfeld 280,

6900 Heidelberg, FRG

\section{Instituto Venezuelano de}

Investigaciones Cientificas,

Apartado 21827 ,

Caracas 1020 A,

Venezuela

1. Wendler, I. et al. Br. med. J. 293, 782-785 (1986).

2. Hunsmann G et al LancetII, 952-953 (1985)

3. Mahnke, Ch. et al. J. virol. Meth. (in the press)

4. Mahnke, Ch. et al. J. virol. Meth. (in the press).

4. Daniel, M.D. et al. Int. J. Cancer 41, 601-608(1988). Andrada-Serpa, M.J. et al. Immun. Lett. 18(1).
(1988).
Rodriquez, L. et al. Lancet ii, 1098-1100 (1985).

6. Rodriquez, L. et al. Lancetii, $1098-1100(1985)$.
7. Volsky, D.J. et al. AIDS Res. Hum. Retroviruses 2(2), 79-92 (1986)

8. Volsky, D.J. et al. N. Engl. J. Med. 10, 647-648 (1985).

9. Merino, F. et al. Int. J. Cancer 34, 501-506 (1984).

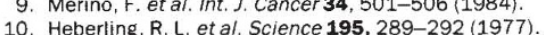

\section{Gyro results}

SIR-I read with great interest the analysis by S. H. Salter (Nature 343, 509-510; 1990) of the gyroscope weight loss reported by $\mathrm{H}$. Hayasaka and S. Takeuchi (Phys. Rev. Lett. 63, 2701-2704; 1989). Salter says that the straight lines of weight loss versus rotational frequency do not meet at a point corresponding to zero weight change for zero rotation. But they do; Salter evidently overlooked the fact that the scale on the abcissa does not start from zero, further regression analysis (done by me) confirms that both lines meet at the origin.

RONALD J. TALLARIDA

Temple University School of Medicine,

Philadelphia,

Pennsylvannia 19140, USA

SIR-Hayasaka and Takeuchi recently reported $^{1}$ anomalies in the weight of rotating gyroscopes. Their results were peculiar in at least two respects. (1) A gyroscope whose angular momentum $\omega$ pointed down reportedly exhibited a weight reduction proportional to $|\omega|$, whereas one with $\omega$ directed upwards exhibited no weight anomaly. (2) The effect was large, the change in gravitational mass of a gyro spinning 'downwards' being

$$
\frac{\Delta m(\kappa)}{m}=\kappa_{\mathrm{eq}} \frac{r_{\mathrm{e}} \omega}{g}
$$

where $r_{\text {eq }}$ is a characteristic radius of the gyroscope, and the coefficient $\kappa=-2 \times$ $10^{-5} \mathrm{~s}^{-1}$. These effects have not been confirmed in two subsequent experiments using macroscopic gyros ${ }^{2.3}$.

Much tighter limits on such anomalous behaviour can be obtained from microscopic gyros. If the effect reported by Hayasaka and Takeuchi applies at the microscopic level, it will not average to zero for unpolarized test bodies. An unpolarized test body will exhibit gravitational mass loss because the weight decrease of particles whose orbital angular momentum $l$ is down is not compensated by a weight gain of particles whose $l$ is up.

A recent comparison of the acceleration of beryllium and copper test bodies in the Earth's gravitational field ${ }^{+}$showed no difference between gravitational and intertial masses at the level $\Delta m / m \leqslant 1.0 \times$ $10^{-11}$. Because the mean $|l|$ of the electrons and nucleons in copper is higher than it is in beryllium, the null results of the beryllium/copper comparison indicate that the inertial masses of particles with $l$ up and $l$ down must differ by precisely the same amount as their gravitational masses. The energies of atomic and nuclear levels are proportional to the inertial masses of the electron and nucleon, respectively. Hence if Hayasaka's and Takeuchi's effect occurs on a microscopic scale there will be anomalous 